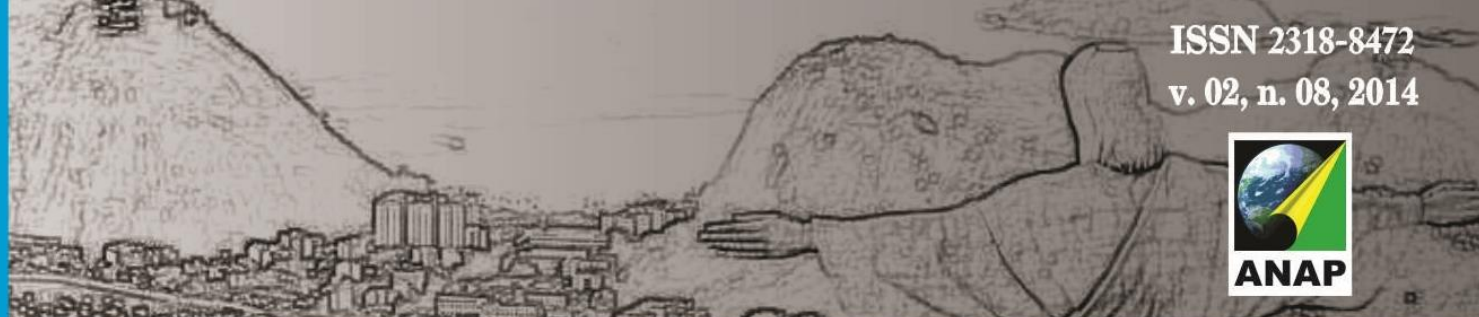

Revista Nacional de

Gerenciamento de Cidades

\title{
ANÁLISE DA MORFOMETRIA DA SUB-BACIA DO CÓRREGO MORUMBI, PIRACICABA/SP
}

\author{
Camila Pontin Novaes ${ }^{1}$
}

Maria Cristina Perusi ${ }^{2}$

\begin{abstract}
RESUMO
As bacias hidrográficas, quando sujeitas ao desordenado processo de ocupação antrópica, tendem a serem submetidas diversos desequilíbrios ambientais, dentre eles, enchentes. Tendo em vista que a maioria da população brasileira vive em área urbana, notória é a importância de se realizar estudos para predizer e mitigar esses impactos negativos. Assim, este trabalho objetiva caracterizar morfométricamente a sub-bacia do Córrego Morumbi, situada no município de Piracicaba/SP, onde boa parte dos fundos de vale urbanos são caracterizados pelo intenso processo de ocupação e onde parte da população é ameaçada pelas enchentes. Dessa forma, avaliou-se a relação das características físicas da bacia com a probabilidade de enchentes ocorrerem na área em questão. $\mathrm{A}$ caracterização morfométrica se deu a partir dos cálculos elaborados no Software "ArcGis 9.3" de índices relacionados à área da sub-bacia, à declividade, ao sistema de drenagem e à forma. Como resultados tem-se a área da sub-bacia: $1,26 \mathrm{~km}^{2}$, portanto, pequena o que equivale dizer que os picos de enchente podem ser acentuados. As declividades encontradas foram baixa e média; um relevo plano e ondulado, não sendo muito significativo para a ocorrência de enchentes. O sistema de drenagem é de primeira ordem e apresentou densidade de drenagem $1,008 \mathrm{~km} / \mathrm{km}^{2}$ apresentando ineficiência na drenagem. $\mathrm{O}$ fator de forma foi de $\mathrm{Kf}=0,52$, o que representa uma tendência mediana a enchentes assim, como o coeficiente de compacidade, $\mathrm{Kc}=1,17$.
\end{abstract}

PALAVRAS-CHAVE: bacia hidrográfica urbana, enchentes, morfometria

\section{MORPHOMETRY ANALYSIS OF SUB-BASIN STREAM MORUMBI, PIRACICABA/SP}

\section{ABSTRACT}

\footnotetext{
${ }^{1} 1$ Mestranda do Programa de Pós-Graduação em Geografia da Faculdade de Ciências e Tecnologia da UNESP - Campus de Presidente Prudente. E- mail: camilapontin@yahoo.com.br

22 Professora Doutora do Departamento de Geografia da UNESP-Campus de Ourinhos. E-mail: cristina@ourinhos.unesp.br
} 


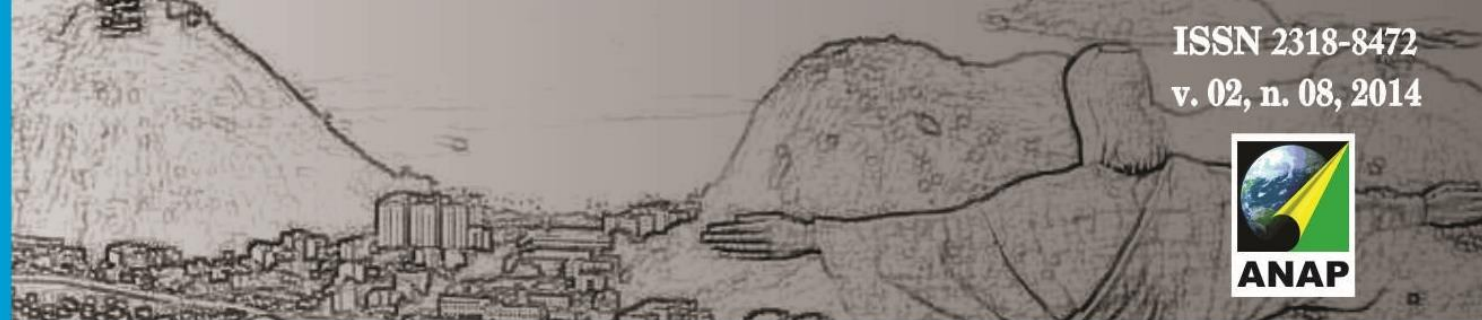

Revista Nacional de

Gerenciamento de Cidades

Watersheds, when subjected to the disorderly process of human occupation, tend to be submitted to various environmental imbalances among them floods. Given that the majority of the population lives in urban area, notorious is the importance of conducting studies to predict and mitigate these negative impacts. Thus, this work aims to morphometrically characterize the sub-basin of the stream Morumbi, located in Piracicaba / SP, where much of the funds of urban valley are characterized by intense process of occupation and where the population is threatened by floods. Thus, we evaluated the relationship between physical characteristics of the basin with the likelihood of flooding occurring in the area in question. The morphometric characterization was made from estimates made in software "ArcGIS 9.3" of indexes related to the area of sub-basin, the slope, the drainage system and form. As a result there is the area of the sub-basin: $1.26 \mathrm{~km} 2$, so small which is to say that the flood peaks can be accented. The slopes found were low and mean; a flat and wavy relief, not being very significant for the occurrence of floods. The drainage system is of first order and showed drainage density 1.008 $\mathrm{km} / \mathrm{km} 2$ presenting inefficient drainage. The form factor was $K f=0.52$, representing a median tendency to flood as well as the coefficient of compactness, $K c=1.17$.

KEY-WORDS: urban catchment, floods, morphometry

\section{MORFOMETRÍA ANÁLISIS DE SUB-CUENCA DEL ARROYO MORUMBI, PIRACICABA/SP}

\section{RESUMEN}

Las cuencas hidrográficas, cuando se somete al proceso desordenado de ocupación humana, tienden a ser sometido a diversos desequilibrios ambientales entre ellos inundaciones. Dado que la mayoría de la población vive en el área urbana es notoria la importancia de realizar estudios para predecir y mitigar estos impactos negativos. Por lo tanto, este trabajo tiene como objetivo caracterizar morfométricamente la sub-cuenca del Arroyo Morumbi, ubicado en Piracicaba / SP, donde gran parte de los fondos de valle urbana se caracterizan por un intenso proceso de ocupación y donde la población se ve amenazada por las inundaciones. Por lo tanto, se evaluó la relación entre las características físicas de la cuenca con la probabilidad de inundación que ocurre en la zona en cuestión. La caracterización morfométrica se dio a partir de cálculos elaborados en "ArcGis 9.3" Software índice relacionado con el área de la subcuenca, la pendiente, el sistema de drenaje y la forma. Como resultado de ello es el área sub-cuenca: $1,26 \mathrm{~km} 2$ tan pequeño que es decir los picos de las inundaciones se pueden mejorar. Las pistas encontradas fueron bajas y la media; un relieve plano y ondulado, de no ser muy significativa para la ocurrencia de inundaciones. El sistema de drenaje es de primer orden y mostró densidad de drenaje 1,008 kilometros / km2 presentando drenaje ineficiente. El factor de forma fue $K f=0,52,10$ que representa una tendencia mediana a las inundaciones, así como el coeficiente de compacidad, $K c=1,17$.

PALABRAS CLAVE: cuenca urbana, inundaciones, morfometría

\section{INTRODUÇÃO}

Os problemas ambientais se concentram de forma expressiva nas áreas urbanas, devido ao modelo de desenvolvimento, onde os processos de urbanização 


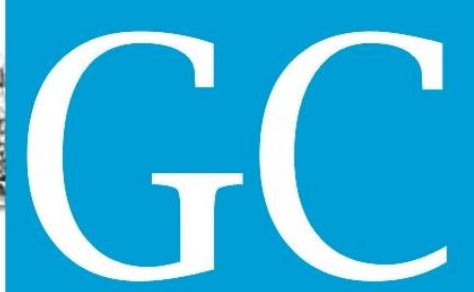

Revista Nacional de

Gerenciamento de Cidades

e industrialização possuem papel fundamental nos danos ambientais, provocados pela pressão sobre o meio físico (GUERRA; MARÇAL, 2006).

A região sudeste do Brasil segue como a mais urbanizada do país, com 92,9\% da população vivendo em zona urbana (IBGE, 2010). Guerra e Cunha (2005) trazem que a concentração urbana no Brasil tem ocorrido de forma pouco planejada, presenciando conflitos institucionais e tecnológicos e tendo como um dos principais problemas relacionados à ocupação urbana as enchentes e seus impactos ambientais.

As bacias hidrográficas, quando sujeitas ao processo desordenado de ocupação, podem ser submetidas a diversos desequilíbrios ambientais. Cunha e Guerra (1999) trazem que as mudanças ocorridas no interior das bacias de drenagem podem ter causas naturais, entretanto, a ação humana tem sido um importante acelerador dos processos de desequilíbrio da paisagem.

Tendo esta problemática em vista, o presente trabalho objetiva caracterizar morfometricamente a sub-bacia do Córrego Morumbi, afluente do Ribeirão Piracicamirim, situada no município de Piracicaba-SP, centro-leste do Estado de São Paulo, onde ocorrem casos de enchentes, relatados pela população. Nessa área, boa parte dos fundos de vale urbanos são caracterizados pelo intenso processo de ocupação e onde o bem-estar da população é ameaçado pelas enchentes.

\section{ESTUDOS EM BACIAS HIDROGRÁFICAS}

A unidade para os estudos hidrológicos, segundo Pompêo (2000) deve ser a Bacia Hidrográfica, uma vez que os transbordamentos de cursos d'água podem se dar por desequilíbrio hidrológico em regiões a montante. Nesse sentido, o que chove nas nascentes e nos afluentes dos rios principais de uma Bacia Hidrográfica contribui com o aumento do volume que corre nos cursos hídricos.

Na Bacia Hidrográfica, "a associação entre o volume de água e a energia potencial resulta em uma enorme capacidade de promover efeitos adversos como o carregamento de todo tipo de sedimento para as áreas mais baixas da bacia" 

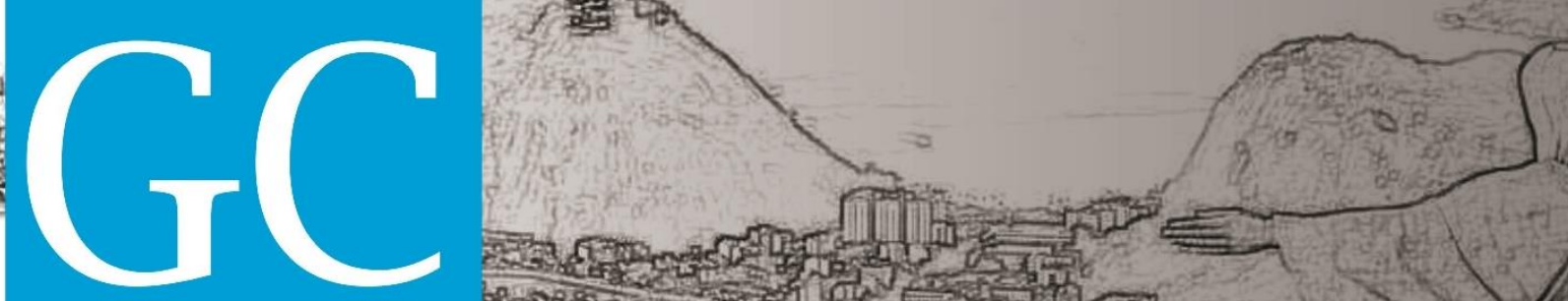

Revista Nacional de

Gerenciamento de Cidades

\section{b) Declividade}

A declividade do terreno controla significativamente a velocidade com que se dá o escoamento superficial, afetando o tempo que leva para a água da chuva concentrar-se nos leitos fluviais que constituem a rede de drenagem das bacias. A magnitude dos picos de enchente e a maior ou menor oportunidade de infiltração, além de suscetibilidade para erosão dos solos, dependem da rapidez com que ocorre o escoamento sobre os terrenos da bacia (VILLELA; MATTOS, 1975). A declividade da bacia é um parâmetro de grande interesse hidrológico, especialmente para as bacias pequenas (LINSLEY et al., 1975 apud BORSATO; MARTONI, 2004). Isso ocorre porque a declividade é um dos fatores principais que regulam a velocidade desse escoamento. Além disso, a declividade vai ter grande influência nos processos de erosão e infiltração. Borsato e Martoni (2004) consideram como baixa declividade de 0 a 12\%; média declividade de 12 a 24\%; média a alta de 24 a $36 \%$; e como alta a muito alta declividade maior que $36 \%$.

De acordo com a Embrapa (1979), os declives entre 0-3\% representam relevos considerados planos, onde os desnivelamentos na topografia são pequenos. Com declividades de 3-8\% o relevo é considerado suavemente ondulado, com a superfície de topografia constituída por colinas e elevações de altitudes relativas da ordem de 50 a 100 metros, com declives suaves. Entre os valores de $8-20 \%$, tem-se um relevo ondulado, com topografia constituída por colinas. Valores acima destes representam relevos fortemente ondulados (25-45\% de declividade), montanhoso ( $45-75 \%$ de declividade) e escarpado (com declives acima de $75 \%$ ).

\section{- Declividade do curso d'água}

De acordo com Strahler (1964), a declividade dos canais está intimamente ligada com a declividade dos terrenos de uma bacia. Vertentes com declividades altas contribuem com uma grande quantidade de detritos maiores em direção aos canais que, por sua vez, devem ter uma declividade alta para poderem efetuar o transporte, ao passo que vertentes com relevo mais suave acabam gerando detritos 


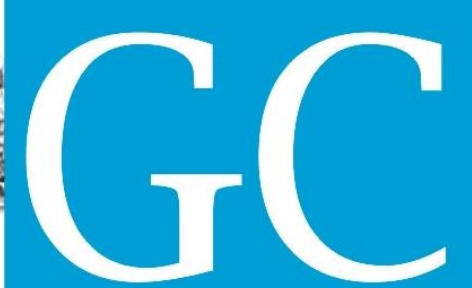

Revista Nacional de

Gerenciamento de Cidades

menores e em menor quantidade, facilitando o transporte pelos rios, que necessitam então de uma declividade menor.

O perfil longitudinal é a representação visual da relação entre a altimetria e o comprimento de determinado curso d'água, entre a nascente e a foz (CHRISTOFOLETTI, 1981). Canais típicos apresentam um perfil longitudinal côncavo para o céu (LINSLEY et al., 1975 apud BORSATO; MARTONI, 2004), com os valores de declividade aumentando em direção à nascente do rio. Segundo Strahler (1964), o perfil longitudinal de quase todos os canais, sob as mais variadas condições climáticas e geológicas, apresentam essa condição.

\section{c) A rede de drenagem}

O tipo de drenagem é importante em razão da eficiência do sistema de drenagem, com as características da hidrografia dependendo deste fator. Quanto mais eficiente for a drenagem, mais rápida é a vazão do curso d'água, e vice-versa. Um sistema de drenagem eficiente é o que drena os escoamentos sem produzir impactos nem no local nem a jusante. (FEAM, 2006) Para Wisler e Brater (1964), as características de uma rede de drenagem são basicamente: ordem dos cursos d'água; extensão; e densidade de drenagem.

\section{- Ordem dos cursos d'água}

A ordem dos rios é uma classificação que reflete o grau de ramificação ou bifurcação dentro de uma bacia. Segundo a Classificação proposta por Horton (1945) citado por Villela e Mattos (1975) os canais de primeira ordem não possuem tributários, os canais de segunda ordem têm afluentes de primeira ordem, os canais de terceira ordem recebem afluentes de canais de segunda e podem receber diretamente canais de primeira ordem e assim por diante. Nesta classificação, a maior ordem é atribuída ao rio principal, valendo esta designação em todo o seu comprimento, desde o exutório da bacia até sua nascente. 


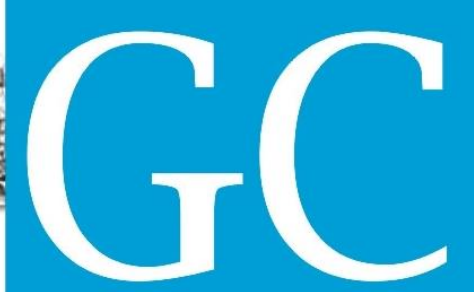

Revista Nacional de

Gerenciamento de Cidades

\section{d) Forma}

A forma da bacia hidrográfica é importante por influenciar no tempo de concentração, ou seja, no tempo necessário para que a partir do início da precipitação toda a bacia contribua na seção em estudo, em suma, é o tempo que leva a água dos limites da bacia para a saída da mesma (VILLELA; MATTOS, 1975). Esse índice representa a proporção com que a água é fornecida ao rio principal durante seu percurso da nascente à foz (WISLER; BRATER, 1964). Isso é verificado por meio dos coeficientes que permitem quantificar a influência da forma no modo de resposta de uma bacia à ocorrência de uma precipitação.

\section{- Fator de forma (Kf)}

O fator de forma indica a relação da forma da bacia com a de um retângulo, correspondendo a razão entre a largura média e o comprimento axial da bacia (da foz ao ponto mais longínquo do espigão) (TONELLO et al, 2006) É um índice que exprime a maior ou menor tendência para enchentes numa bacia. Uma bacia com um fator de forma baixo tem menos tendência para cheias que uma bacia do mesmo tamanho, mas com um fator de forma superior (VILLELA; MATTOS, 1975). O fator de forma kf é a relação entre a largura média $\bar{L}$ e o comprimento mais longo $L$ da bacia. O comprimento mais longo $L$ é a distância desde o início da secção considerada até à cabeceira mais distante da bacia. (WISLER; BRATER, 1964)

Uma bacia com Kf baixo, ou seja, com o L grande, terá menor propensão a enchentes que outra com mesma área, mas de $\mathrm{Kf}$ maior. Isto se deve a fato de que, numa bacia estreita e longa ( $\mathrm{Kf}$ baixo), haver menor possibilidade de ocorrência de chuvas intensas cobrindo simultaneamente toda a sua extensão (VILLELA; MATTOS, 1975). Quanto maior o tempo de concentração, menor a vazão máxima de enchente, se mantidas constantes as outras características. (TONELLO et al., 2006). 


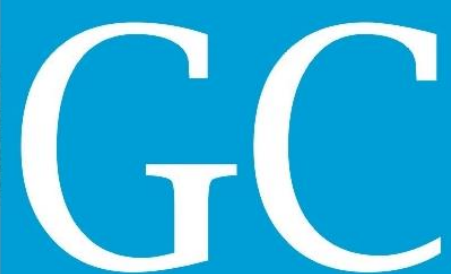

Revista Nacional de

Gerenciamento de Cidades

Figura 1. Mapa da área da sub-bacia do Córrego Morumbi

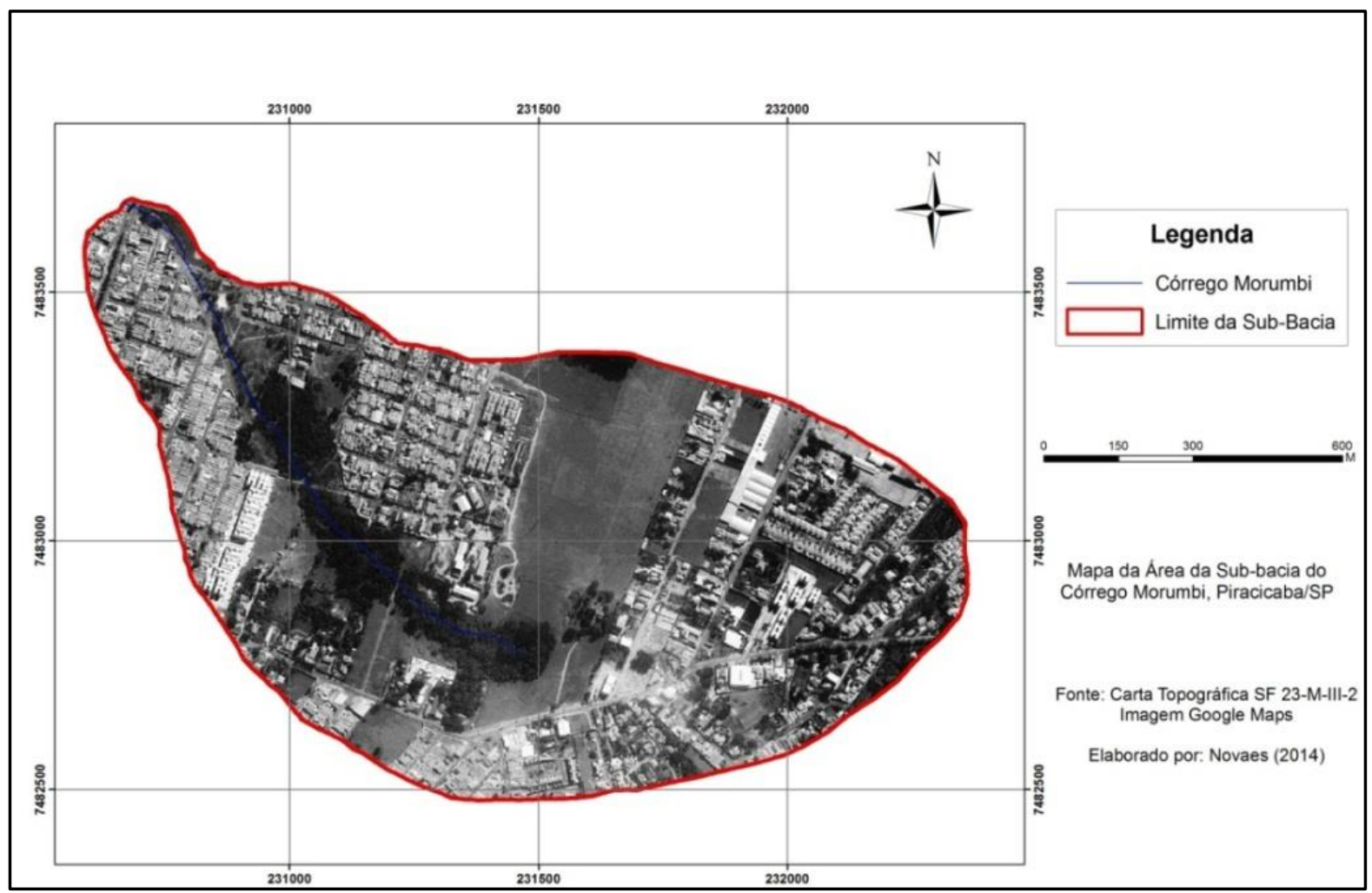

Elaborado por: Novaes (2014)

A delimitação da área da sub-bacia hidrográfica do córrego Morumbi, Piracicaba/SP foi feita a partir das curvas de nível, nas quais os divisores topográficos ou divisores de água são as cristas das elevações do terreno que separam a drenagem da precipitação entre duas bacias adjacentes formando uma linha fechada. A base foi a Carta Topográfica de Piracicaba do IBGE (1969), Folha SF 23-Y-A-I-V, na escala 1:50.000. Utilizou-se imagens do Satélite Landsat do ano de 2005, digitalizadas no Software "ArcGis 9.3", programa que a partir da delimitação calcula a área, expressa em hectares (ha) ou quilômetros quadrados $\left(\mathrm{km}^{2}\right)$.

Para a declividade da sub-bacia foi utilizada a Carta Topográfica de Piracicaba (IBGE, 1969), onde através da digitalização das curvas de nível, elaborado no software "ArcGis 9.3", determina-se em porcentagem as declividades. 

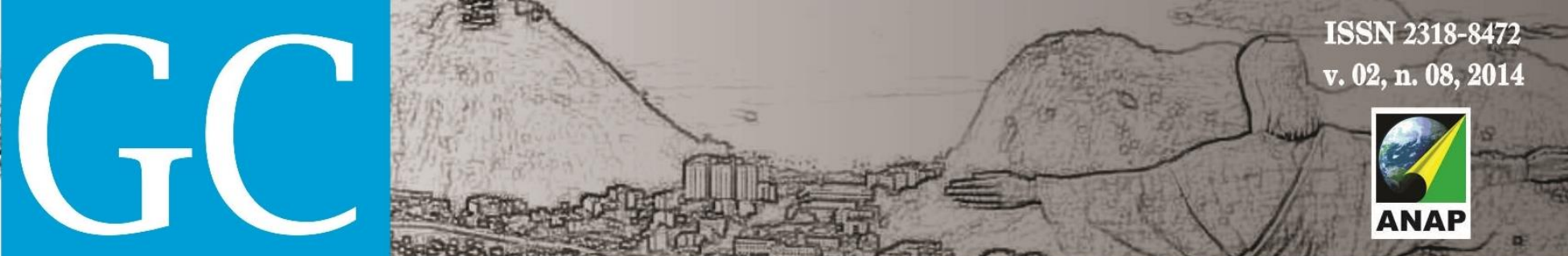

\section{Revista Nacional de}

Gerenciamento de Cidades

\section{RESULTADOS E DISCUSSÃO}

A delimitação da área da sub-bacia do Córrego Morumbi (Figura 2), resultou na medida de $1,26 \mathrm{~km}^{2}$ ou 126 ha. Essa medida demonstra que a sub-bacia em questão é considerada pequena. Quanto maior a área, menos pronunciados serão os picos de enchentes. Desta forma, entende-se que uma bacia de área menor apresentará picos maiores, pois menor será o tempo para que toda a bacia contribua de uma só vez durante uma precipitação.

Figura 2. Delimitação da área da Sub-bacia do Córrego Morumbi

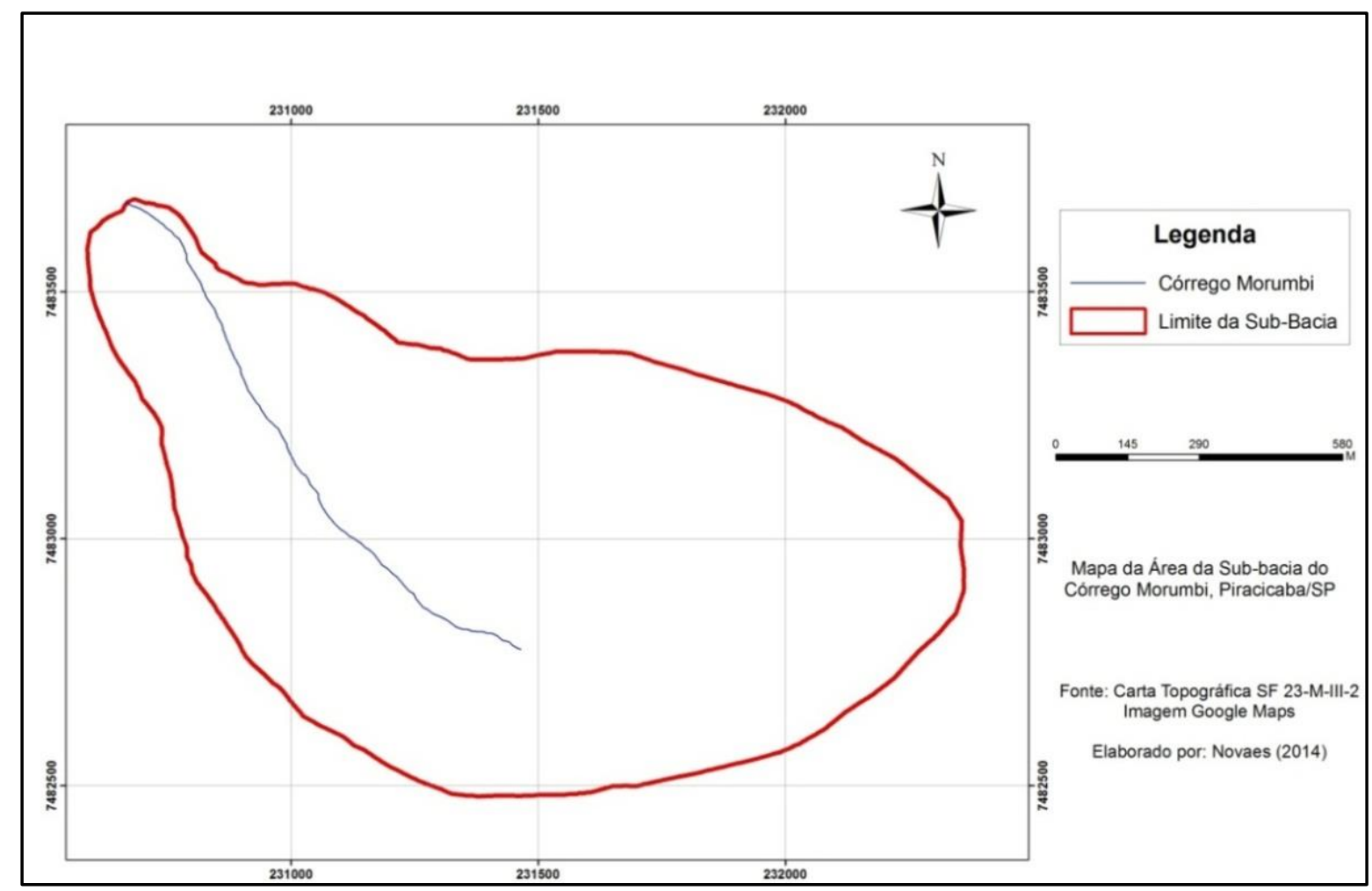

Elaborado por: Novaes (2014)

A Figura 3 representa as classes de declividade da área em questão. Constata-se que há o predomínio da classe de 0-3\%, seguido pelos intervalos de 3$6 \%, 6-12 \%, 12-20 \%$ (Tabela 1), o que representa a predominância de baixa e média declividade (BORSATO; MARTONI, 2004). Esse parâmetro também qualifica o 


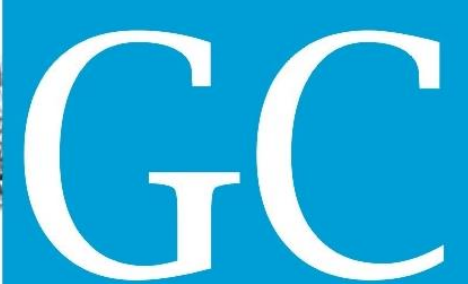

\section{Revista Nacional de}

Gerenciamento de Cidades

relevo como planos, suavemente ondulado e ondulado (EMBRAPA, 1979). A dominância da declividade baixa revela que a velocidade de escoamento superficial será baixa, sendo uma maior quantidade de água armazenada no solo e resultará em enchentes menos pronunciadas. Isso desconsiderando-se o fator de impermeabilização.

Figura 3. Mapa de declividade da Sub-bacia do Córrego Morumbi

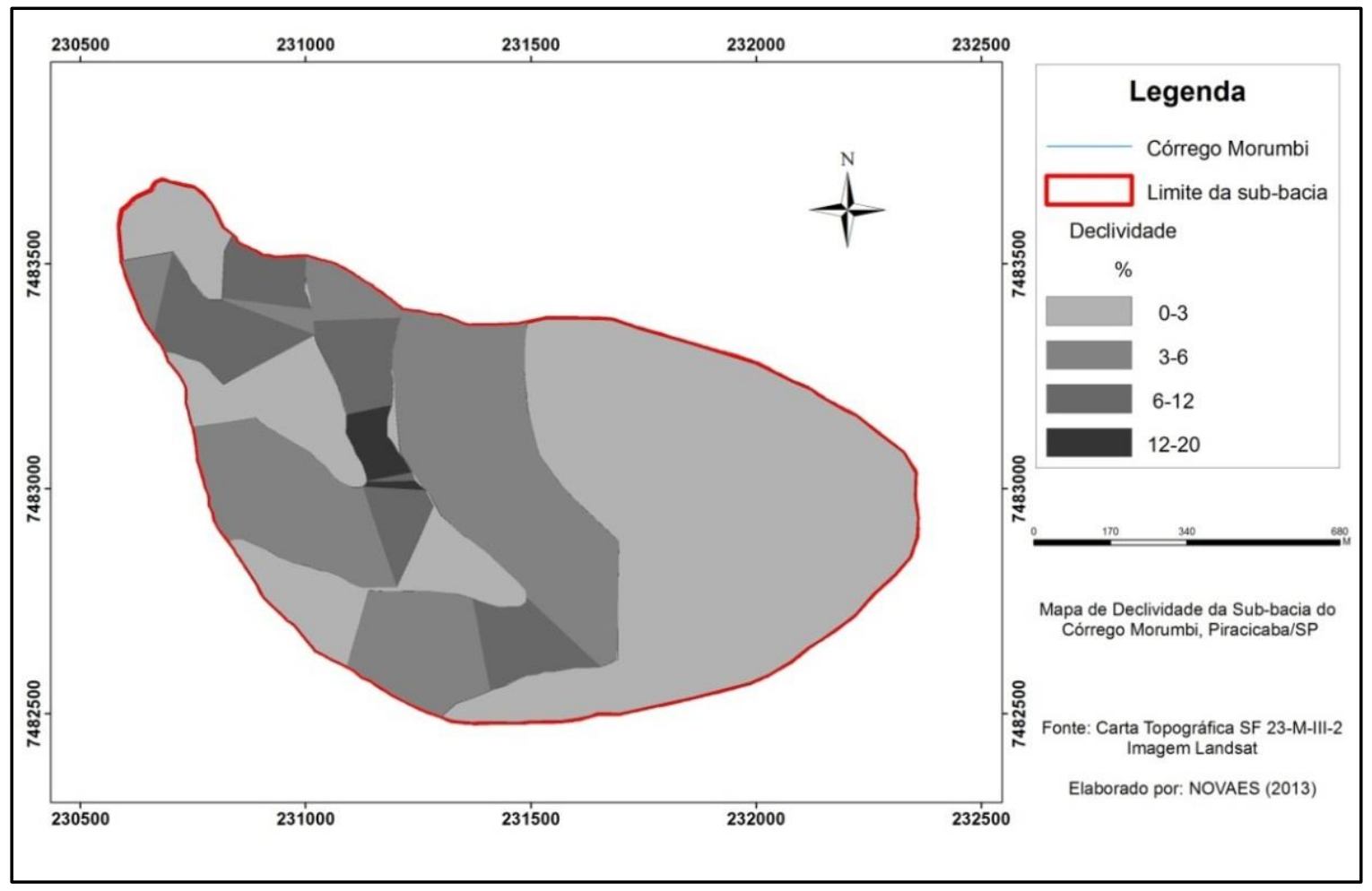

Elaborado por: Novaes (2013)

Tabela 1. Declividades da Sub-bacia do Córrego Morumbi

\begin{tabular}{c|c|c|c}
\hline Declividade & Relevo & Área em $\mathbf{~ k m}^{2}$ & Área em \% \\
\hline $0-3 \%$ & Plano & 0,5 & 40 \\
\hline $3-6 \%$ & Suave ondulado & 0,4 & 33 \\
\hline $6-12 \%$ & Suave ondulado/ Ondulado & 0,3 & 24 \\
\hline $12-20 \%$ & Ondulado & 0,06 & 3 \\
\hline \multicolumn{2}{|c}{ Adaptado de EMBRAPA (1999) }
\end{tabular}



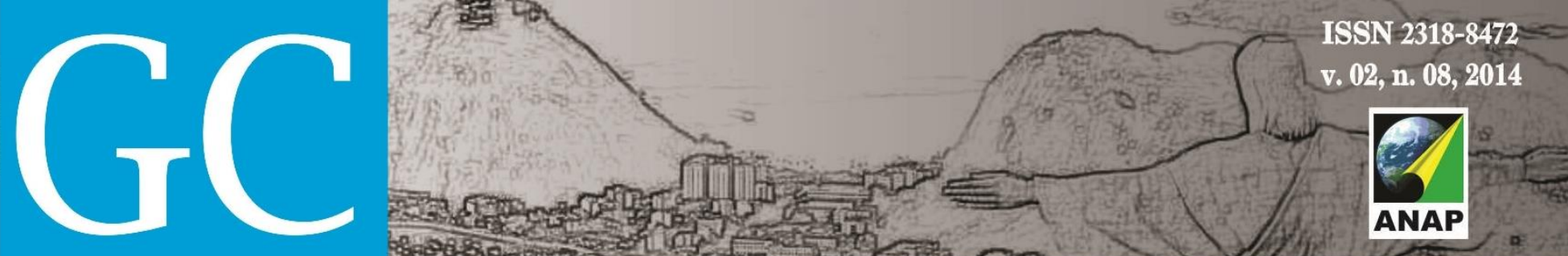

Revista Nacional de

Gerenciamento de Cidades

TONELLO, K.C.; DIAS, H.C.T.; SOUZA, A.L.; RIBEIRO, C.A.A.S.; LEITE, F.P. Morfometria da bacia hidrográfica da Cachoeira das Pombas, Guanhães - MG. In: Revista Árvore, Viçosa-MG, v.30, n.5, p.849-857, 2006.

TUCCI, C.E.M. Inundações Urbanas. In: TUCCI, C.E M.; PORTO, R.L. ; BARROS, M.T. (org.)

Drenagem Urbana. Porto Alegre, Editora da Universidade, 1995, p.15-36.

VIANNA, A. P. P. Utilização de modelagens hidrológica e hidráulica Associadas a um sistema de informações geográficas para mapeamento de áreas inundáveis - Estudo de caso: município de Itajubá, MG. Dissertação de Mestrado, Belo Horizonte, 2000, MG.

VILLELA, S.M.; MATTOS, A. Hidrologia aplicada. São Paulo: Mcgraw Hill, 1975.

VITTE, A.C.; VILELA FILHO, L.R. Utilização da morfometria na determinação da fragilidade potencial do relevo na bacia hidrográfica do Córrego Proença, município de Campinas (SP). In: VI Simpósio Nacional de Geomorfologia. Goiânia-GO, Set 6-10, 2006.

WISLER, C.O.; BRATER, E.F. Hidrologia. Rio de Janeiro: Ao Livro Técnico, 1964. 